Jpn. J. Med. Mycol.

Vol. 47, 219-224, 2006

ISSN 0916-4804

Original Article

\title{
Isolation and Characterization of a Novel Elastase Inhibitor, AFLEI from Aspergillus flavus
}

\author{
Yoshiyuki Okumura ${ }^{1}$, Kenji Ogawa ${ }^{2}$, Kei-ichi Uchiya ${ }^{3}$, \\ Toshiaki Nikai ${ }^{3}$ \\ ${ }^{1}$ Department of Quality Control, Mathuurayakugyo Co., Ltd., \\ 24-21 Enjo-chou, Syowa-ku, Nagoya, Aichi 466-0054, Japan \\ ${ }^{2}$ Department of Pulmonary Medicine, Higashi Nagoya National Hospital, \\ 5-101 Umemorizaka, Meito-ku, Nagoya, Aichi 465-8620, Japan \\ ${ }^{3}$ Department of Microbiology, Faculty of Pharmacy, Meijo University, \\ 150 Yagotoyama, Tempaku-ku, Nagoya, Aichi 468-8503, Japan \\ 〔Received: 13, February 2006. Accepted: 4, April 2006]
}

\begin{abstract}
A novel elastase inhibitor from Aspergillus flavus (AFLEI) was isolated, and biochemical properties of AFLEI were examined. Column chromatography using diethylaminoethyl (DE) 52-Cellulose and Sephadex G-75 was used to purify the inhibitor. The final preparation was found to be homogeneous as indicated by a single band after disc polyacrylamide gel (PAGE) and isoelectric focusing electrophoreses. AFLEI had a molecular weight of 7,525.8 as determined by TOF-MS (time of flight mass spectrometry). The elastolytic activity of elastases from A. flavus, A. fumigatus and human leukocytes were inhibited by AFLEI. However, this activity from porcine pancreas elastase, trypsin, chymotrypsin, thrombin, and $\mathrm{Ac}_{1}$-Proteinase from snake venom was not affected by AFLEI. The fibrinogenase activity of the elastase from A. flavus was inhibited by AFLEI. AFLEI was inhibited by $\alpha_{2}$-macroglobulin. However, ethylenediaminetetraacetic acid (EDTA-2Na), benzamidine, chymostatin, tosyl phenylalanine chloromethyl ketone (TPCK) and dithiothreitol (DTT) did not show any inhibitory effect on the elastase inhibitory activity of AFLEI.
\end{abstract}

Key words: Aspergillus flavus, elastase inhibitor, isolation, property

\section{INTRODUCTION}

Aspergillosis is a common mycosis in immunocompromised hosts undergoing chemotherapy. It is caused by inhalation of high spore concentrations of the Aspergillus species. It is reported that various proteases are produced from A. fumigatus $^{1-5)}$, A. flavus ${ }^{6,7)}$ and A. niger ${ }^{8,9)}$. Since $28 \%$ of lung tissue is composed of elastin, a strong relationship is suggested between elastase and the pathogenesis of aspergillosis.

From a practical standpoint, elastase-producing strains promote a higher death rate in immunodeficient mice than non-elastase producing strains. Elastase-producing strains destroy

Corresponding author: Toshiaki Nikai

Department of Microbiology, Faculty of Pharmacy, Meijo University,

150 Yagotoyama, Tempaku-ku, Nagoya 468-8503, Japan lung tissue ${ }^{10,11)}$ and an elastase produced by Aspergillus has been confirmed as a definitive virulence factor of aspergillosis ${ }^{12)}$.

Frosco et al. ${ }^{13)}$ observed that the purified monoclonal antibody to elastase derived from A. fumigatus possesses the ability to inhibit the elastase produced by A. fumigatus. Ulinastatin, which contains an enzyme inhibitor, was administered by way of intravenous drip infusion concomitantly with antifungal agents to patients of pulmonary aspergillosis ${ }^{14-18)}$. It is very likely that the elastase inhibitor is an effective therapy of aspergillosis.

It has been shown that $A$. fumigatus and $A$. flavus produced elastase inhibitors ${ }^{19)}$, although it had not previously been know that Aspergillus spp. produced this elastase inhibitor. A novel elastase inhibitor from Aspergillus flavus (AFLEI) is the first reported isolation of an elastase 
inhibitor from A. flavus. In this paper, we report the isolation, and biochemical properties of a novel elastase inhibitor from A. flavus (AFL-1 strain) from a patient.

\section{MATERIALS AND METHODS}

\section{Strain and Reagents}

Aspergillus flavus (AFL-1 strain) was identified and isolated from sputum from a patient with allergic bronchopulmonary aspergillosis. Elastases from A. flavus and A. fumigatus were purified by the method of Hasegawa et al. ${ }^{2,7)}$. Succinyl L-alanyl- L-alanyl- L-alanyl p-nitroanilide (STANA) was purchased from the Peptide Institute Inc. (Osaka, Japan). Yeast carbon base and casamino acids were obtained from Difco Lab., (Detroit, MI, USA). Elastin, elastase from porcine pancreas and human leukocytes, trypsin, chymotrypsin and N-1-naphtyletylenediamine dihydrochloride were from Sigma Chemical Co., Ltd. (St. Louis, MO, USA). Sodium nitrite, fibrinogen and dimethylsulfoxide (DMSO) were procured from Katayama Chemical Industry, Ltd. (Osaka). Ammonium sulfamate and collagen (Type I, II, III, IV) were supplied from Wako Pure Chemical Industries, Ltd. (Osaka). Membrane filters were purchased from Advantec Toyo Co., Ltd. (Tokyo, Japan). DE52-Cellulose was obtained from Whatman Biochemical (Clifton, NJ, USA). Sephadex G-75 was purchased from Pharmacia (Uppsala, Sweden). $\alpha_{2}$-Macroglobulin was supplied from Boehringer Mannheim (Mannheim, Germany). Thrombin was obtained from Mochida Pharmaceutical Co., Ltd. (Tokyo). Proteinase from $S$. epirermidis was prepared in this laboratory. Other chemicals used were of analytical grade and purchased from commercial sources.

\section{Production of elastase inhibitor}

A sufficient number of microorganic spores were cultured in $100 \mathrm{ml}$ synthetic medium of $0.1 \%$ yeast carbon base containing $1 \%$ casamino acid as a nitrogen source. The cultures were incubated for 7 days at $37^{\circ} \mathrm{C}$ without shaking. The culture broth was filtered aseptically through a $0.22 \mu \mathrm{m}$ pore size membrane filter, and the cell-free culture supernatant was used as the source of crude inhibitor.

\section{Assay for elastolytic activity}

Elastolytic activity of the elastase was assayed by the method of diazocoupling measuring $p$ nitroanilide ( $\mathrm{p}-\mathrm{NA}$ ) released from $50 \mathrm{mM}$ STANA in DMSO, which was used as the substrate. To determine the extent of STANA digestion, 0.1 $\mathrm{m} l$ of the enzyme solution and $0.9 \mathrm{~m} l$ of 50
$\mathrm{mM}$ Tris-HCl buffer, pH 7.5, and $20 \mu l$ of 50 $\mathrm{mM}$ STANA solution were incubated for 60 $\min$ at $37^{\circ} \mathrm{C}$. The reaction was stopped by adding $1 \mathrm{ml}$ of $10 \%$ trichloroacetic acid (TCA). Then $0.2 \mathrm{~m} l$ of $0.1 \%$ sodium nitrite, $0.5 \%$ ammonium sulfamate and $0.1 \% \mathrm{~N}-1$-naphtyletylenediamine dihydrochloride were added to the reaction solution and the color developed was read at $550 \mathrm{~nm}$. One unit of STANA hydrolase activity was defined as the amount of enzyme which hydrolyzed one micromol of substrate per minute.

Effects of AFLEI on fibrinogenase and collagenase activities of elastase

Elastase from A. flavus in $10 \mathrm{mM}$ Tris-HCl buffer ( $\mathrm{pH}$ 8.5) was incubated with AFLEI for $15 \mathrm{~min}$, and with $1 \mathrm{mg}$ of fibrinogen or collagen (Type I, II, III, IV) at $37^{\circ} \mathrm{C}$ for various time intervals. Following incubation, $0.1 \mathrm{ml}$ of the above reaction mixture was withdrawn for an assay of clottable fibrinogen. Simultaneously, 0.1 $\mathrm{m} l$ of the reaction mixture was pipetted into a small test tube and $0.1 \mathrm{~m} l$ of buffer containing $10 \mathrm{M}$ urea, $4 \%$ sodium dodecyl sulfate, $10 \mathrm{mM}$ phosphate buffer ( $\mathrm{pH} 7.2$ ), and 3\% $\beta$-mercaptoethanol were added. This solution was incubated at $37^{\circ} \mathrm{C}$ for $6 \mathrm{hr}$. An aliquot of $20 \mu \mathrm{l}$ was then electrophoresed on a $12 \%$ SDS-polyacrylamide gel.

\section{RESULTS}

\section{Purification of AFLEI}

A sufficient number of microorganic spores were cultured in $100 \mathrm{ml}$ of broth. Elastase inhibitory activity $(100 \sim 95 \%)$ was found in 5 8 day culture supernatants. The cultures were incubated for 7 days at $37^{\circ} \mathrm{C}$ without shaking. Elastase inhibitory activity of the culture supernatant was measured (Fig. 1A). The culture broth was filtered, and the cell-free culture supernatant was used as the source of crude inhibitor. Solid ammonium sulfate was added (60\% saturation) to $100 \mathrm{ml}$ of the culture filtrate supernatant from A. flavus at room temperature. The resulting precipitate was collected by centrifugation at 3,000 r.p.m. at $10 \mathrm{~min}$, and dissolved in an equal volume of the original supernatant in 10 $\mathrm{mM}$ Tris-HCl buffer ( $\mathrm{pH} 7.5)$. This solution was applied on a DE52-Cellulose equilibrated with $10 \mathrm{mM}$ Tris-HCl buffer ( $\mathrm{pH}$ 7.5). The column was eluted with equilibration buffer and $10 \mathrm{mM}$ Tris-HCl buffer ( $\mathrm{pH} 7.5$ ) containing a $0.5 \mathrm{M}$ $\mathrm{NaCl}$ gradient (Fig. 1B). Inhibitory activity (100 $\sim 50 \%$ ) was found in fraction numbers 170 190. The fraction numbers $170 \sim 190$ were 


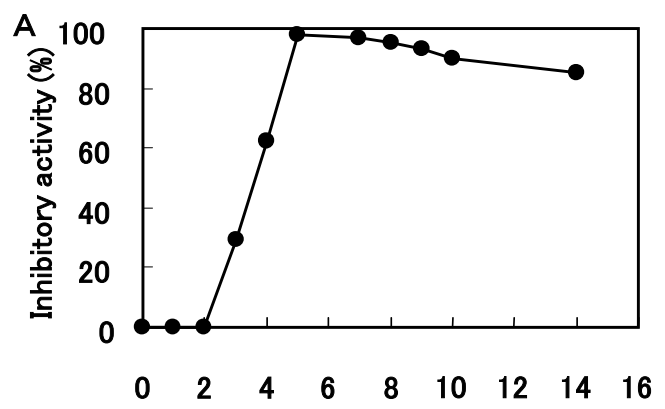

Cultivation time (day) of Aspergillus flavus
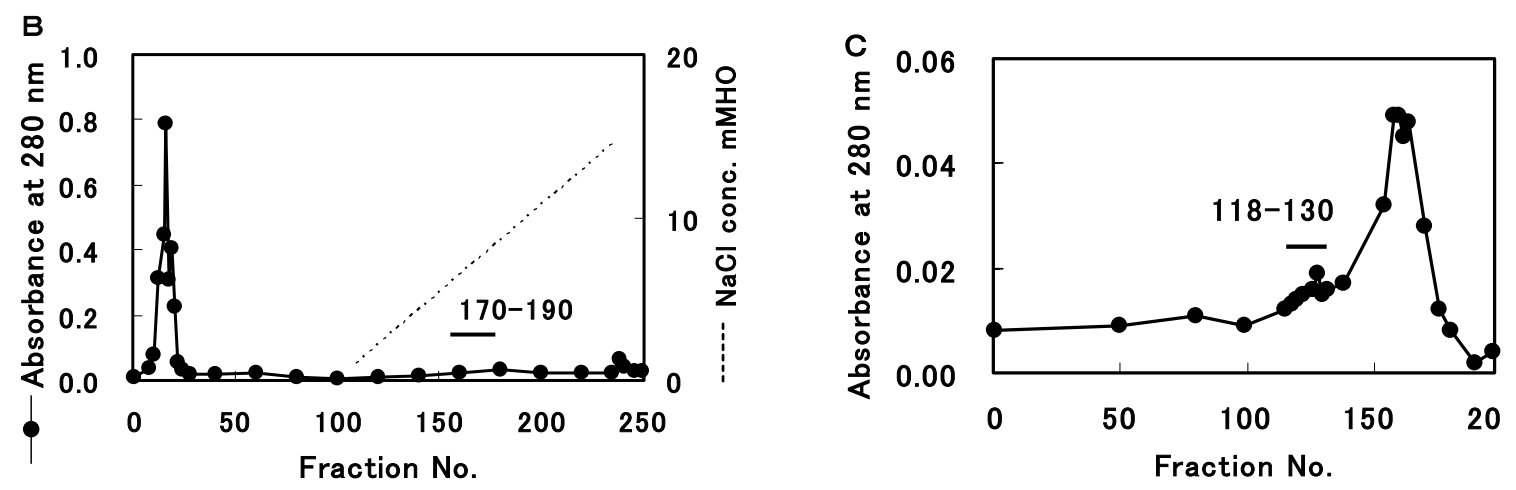

Fig. 1. Elastase inhibitory activity and column chromatography of culture filtrate from A. flavus.

(A) Elastase inhibitory activity of culture filtrate from A. flavus.

(B) DE52-Cellulose column chromatography.

(C) Sephadex G-75 column chromatography.

pooled, concentrated by lyophilization, and applied to a column of Sephadex G-75 equilibrated with $10 \mathrm{mM}$ Tris-HCl buffer ( $\mathrm{pH} 7.5$ ). Inhibitory activity was found in fraction numbers 118 130 (Fig. 1C). These fraction numbers were then pooled and analyzed using polyacrylamide gel electrophoresis. AFLEI was electrophoretically homogeneous as demonstrated by polyacrylamide gel electrophoresis ( $\mathrm{pH} \mathrm{8.3)}$ and isoelectric focusing/ polyacrylamide gel. The yield from this purification procedure was $30 \mu \mathrm{g}$ of AFLEI.

\section{Properties of AFLEI}

The molecular weight of the inhibitor isolated from A. flavus was 7,525.8 as determined by TOF-MS (Fig. 2). The pI value was found to be 7.4 by isoelectric focusing/polyacrylamide gel electrophoresis. Carbohydrate content of AFLEI was calculated to be $0 \%$ using glucose as a standard by the method of Morris ${ }^{20)}$. The heat stability of AFLEI $(0.2 \mu \mathrm{g})$ was investigated in $10 \mathrm{mM}$ Tris- $\mathrm{HCl}$ buffer ( $\mathrm{pH}$ 7.5) containing $10 \mathrm{mM} \mathrm{NaCl}$. The inhibitor was heated for 10 min at $37^{\circ} \mathrm{C}, 50^{\circ} \mathrm{C}, 60^{\circ} \mathrm{C}, 80^{\circ} \mathrm{C}$, and $100^{\circ} \mathrm{C}$, then cooled quickly to $4^{\circ} \mathrm{C}$, and inhibitory activity was determined. AFLEI was stable to heat treatment (it remained $50 \%$ active at $80^{\circ} \mathrm{C}$ ).
AFLEI $(0.2 \mu \mathrm{g})$ was incubated at $4^{\circ} \mathrm{C}$ for $24 \mathrm{hr}$ in buffers at various $\mathrm{pH}$ values $(100 \mathrm{mM}$ acetate buffer, $\mathrm{pH} \mathrm{6;} 100 \mathrm{mM}$ Tris-HCl buffer, $\mathrm{pH} \mathrm{7,} \mathrm{8,}$ 9; $100 \mathrm{mM}$ sodium hydrogen carbonate buffer, $\mathrm{pH} 10)$ and the inhibitory activity was determined. It was stable over the $\mathrm{pH}$ range of 6-10.

The effect of various inhibitors on AFLEI was also determined. AFLEI was mixed with the inhibitors and incubated for $15 \mathrm{~min}$ at $37^{\circ} \mathrm{C}$ prior to the addition of STANA as substrate to determine the inhibitor effect on its inhibitory activity. AFLEI was shown to be inhibited about $60 \%$ only by $\alpha_{2}$-macroglobulin. EDTA, benzamidine, chymostatin, TPCK and DTT did not show any inhibitory effect on the elastolytic activity of AFLEI (Table 1).

The effect of AFLEI on various elastases was determined and is shown in Table 2. Fifty microliters of AFLEI was mixed with $50 \mu l$ of the purified elastase from $A$. flavus and incubated for $15 \mathrm{~min}$ at $37^{\circ} \mathrm{C}$. Then, $0.9 \mathrm{ml}$ of $50 \mathrm{mM}$ Tris-HCl buffer, $\mathrm{pH} 7.5$, and $20 \mu l$ of 50 mM STANA solution were added and incubated for $60 \mathrm{~min}$ at $37^{\circ} \mathrm{C}$. The reaction was stopped by adding $1 \mathrm{~m} l$ of $10 \%$ TCA. Two-tenths $\mathrm{m} l$ of $0.1 \%$ sodium nitrite, $0.5 \%$ ammonium sulfamate, and $0.1 \% \mathrm{~N}$-1-naphtyletylenediamine dihydrochloride 


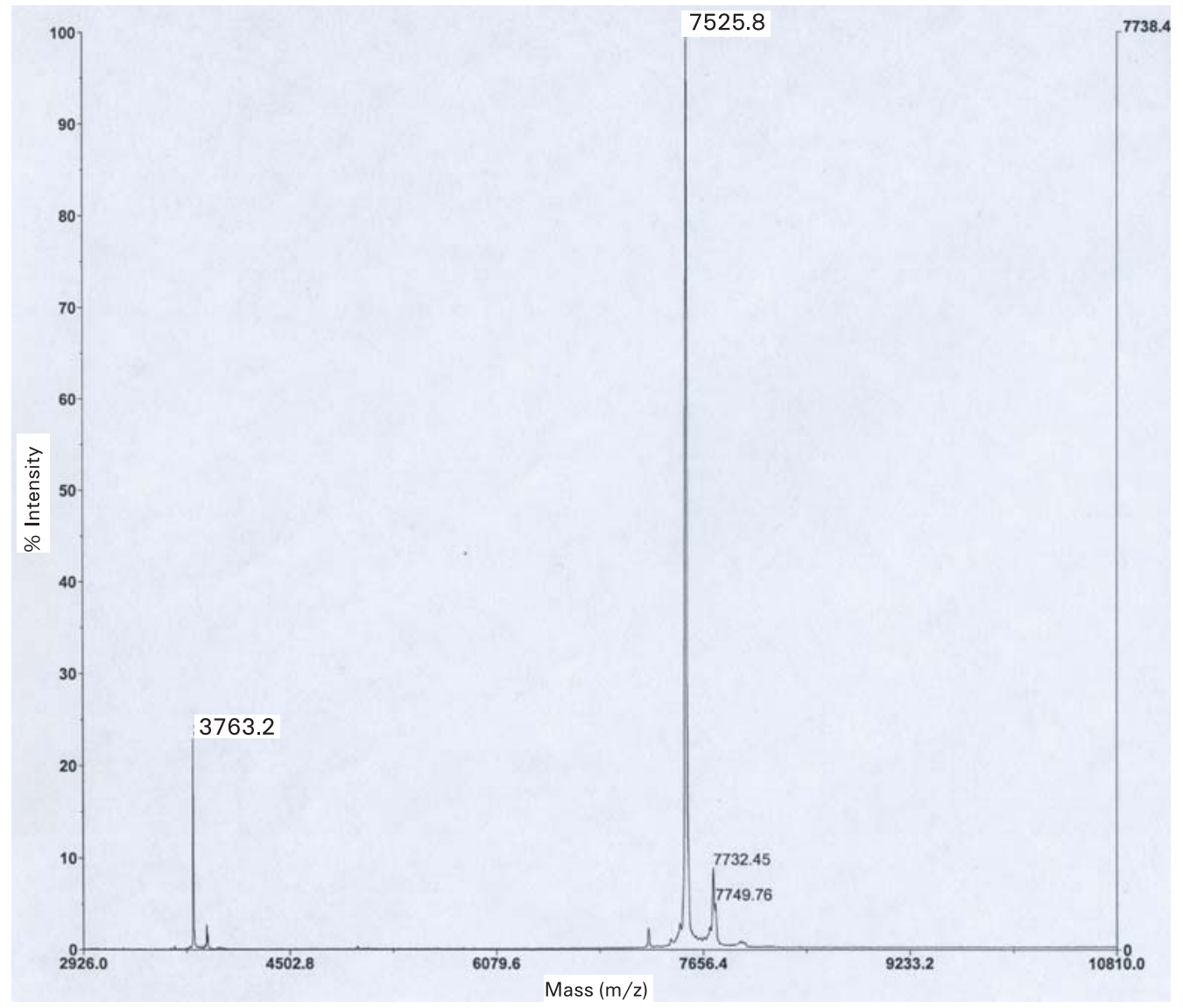

Fig. 2. Time of flight mass spectrometry of AFLEI.

Table 1. Effects of some inhibitors on AFLEI

\begin{tabular}{ccc}
\hline Inhibitor & Final concentration & Residual activity (\%) \\
\hline None & - & 100.0 \\
$\alpha_{2}$-macroglobulin & $1 \mathrm{mg} / \mathrm{m} l$ & 41.0 \\
EDTA & $10 \mathrm{mM}$ & 82.5 \\
SBTI & $5 \mathrm{mg} / \mathrm{m} l$ & 92.6 \\
Chymostatin & $0.1 \mathrm{mg} / \mathrm{m} l$ & 100.0 \\
DTT & $2.5 \mathrm{mM}$ & 100.0 \\
Benzamidine & $5 \mathrm{mM}$ & 99.7 \\
\hline
\end{tabular}

EDTA: ethylenediaminetetraacetic acid-2Na

SBTI: soybean trypsin inhibitor

DTT: dithiothreitol

were then added to the solution and the color that developed was read at $550 \mathrm{~nm}$. One unit is defined as the minimal inhibitory dose which did not release p-NA from STANA per minute. Elastases from A. fumigatus, A. flavus and human leukocytes were inhibited $100 \%, 96.1 \%$ and $72.8 \%$ by AFLEI. However, porcine pancreas elastase was not inhibited.

The effects of AFLEI on fibrinogenase and collagenase activities of elastase were measured by the method of Ouyang and Teng ${ }^{21)}$. Both activities were completely inhibited by AFLEI.
Table 2. Inhibitory activity on some elastases and proteinases of AFLEI

\begin{tabular}{lc}
\hline Elastase and Proteinase & Inhibitory activity (\%) \\
\hline Purified elastase from A. flavus & 100.0 \\
Purified elastase from A. fumigatus & 96.1 \\
Purified elastase from Human leukocyte & 72.8 \\
Purified elastase from Porcine pancreas & 5.5 \\
Fibrinogenase activity & \\
$\quad$ of elastase from A. flavus & + \\
Collagenase activity & + \\
$\quad$ of elastase from A. flavus & 0 \\
Alkaline proteinase from P. aeruginosa ${ }^{22)}$ & 22.3 \\
Ac 1 -proteinase from Agkistrodon acutus & \\
Proteinase from S. epidermidis & 0 \\
Trypsin & 10.2 \\
Chymotrypsin & 20.0 \\
Thrombin & 0 \\
\hline
\end{tabular}

+) inhibition

\section{DISCUSSION}

Aspergillosis is a common mycosis in immunocompromised hosts undergoing chemotherapy. The pathogenesis of aspergillosis is not clearly understood however the literature results of this research strongly indicate that proteases are significant factors in the pathogenic process 
and several of these proteases have been isolated. Frosco et al. ${ }^{1)}$ purified an elastase of 32,000 from A. fumigatus which was inhibited by EDTA. Monod et al. ${ }^{5}$ purified an alkaline protease of 33,000. Rhodes et al. ${ }^{6)}$ purified an elastolytic protease of 23,000 from A. flavus. This laboratory purified an elastolytic protease from A. fumigatus, which had a M.W. and pI of 32,000 and 9.1, respectively ${ }^{2)}$, and proved pathogenicity of elastase. Additionally, we purified an elastolytic glycoprotein protease from $A$. flavus, which was inhibited by diisopropyl fluorophosphate. Its M.W. and pI were 40,000 and 8.6 , respectively ${ }^{7}$.

Kolattukudy et al. ${ }^{24)}$ purified an elastolytic serine protease of 33,000 from A. fumigatus and determined the primary structure by using an elastin medium. They compared the lethal activity of the elastase producing strain and nonelastase producing strain and reported that the former exhibited lethal activity. They did find that the non-elastase producing strain possessed lethal activity but at a significantly minimal level. Kothary et $a l .{ }^{10)}$ compared the lethal activity of six strains of elastase producing and four strains of non-elastase producing $A$. fumigatus and their results were comparable to Kolattukudy et al. ${ }^{24)}$ Furthermore, when the dead murine pulmonary tissue was examined, it was found that elastase producing strains had more broadly invaded the tissue than nonelastase producing strains. Monod et al. ${ }^{5}$ ) reported a similar result with an alkaline protease-deficient mutant, and Blanco et al. ${ }^{12)}$ presented results on the participation of elastase in pathogenicity. From these results, elastase is very important as pathogen factor.

In a previous report, screening of the elastase inhibitor from Aspergillus was examined ${ }^{19)}$ with the finding that $A$. fumigatus and A. flavus did indeed produce an elastase inhibitor. In this report and using the AFL-1 strain, both elastase activity and inhibitor activity were stronger than in the previous 13 strains used.

Development of the material which inhibits leucocyte elastase for the purpose of suppressing internal inflammation is the present focus. For example, ONO-5046 25) is used for the treatment of acute lung disturbance with a general inflammatory reaction symptom-complex. This report is the first that reveals an inhibitor capable of inhibiting leucocyte elastase.

Ogawa et $a l .{ }^{17}$ ) reported a clinical effect with a protease inhibitor. When Aspergillus invades the body, it must have nutrients to live. Therefore, it is thought that Aspergillus produces a strong elastase which breaks human tissue and supplies nutrients. Development of Aspergillus weakens, however, if this can be controlled and a rise in the therapeutic effect will result. The selectivity is high, molecular weight is 7,525.8, it is stable to heat and $\mathrm{pH}$, and, as stated above, possesses sufficient potency to intervene in the pathogenic process of Aspergillosis.

In the future we plan to examine AFLEI in more detail by studying it in vivo and focusing on the possibility of using this inhibitor as another drug in the arsenal to prevent Aspergillosis.

\section{ACKNOWLEDGMENTS}

This research was financially supported by a Grant-in-Aid for High-Tech Research Center Project from the Ministry of Education, Culture, Sports, Science and Technology of Japan, which are gratefully acknowledgement. The authors express thanks to Noriko Sugiyoshi, Ayumi Kondou, Masayo Iguchi, Akiko Hirofuzi, Sayaka Uenuma, Natsu Sato and Chisato Sugimura for technical support.

\section{REFERENCES}

1) Frosco M, Chase $T$ Jr, Macmillan JD: Purification and properties of the elastase from Aspergillus fumigatus. Infect Immun 60: 728734, 1992.

2) Hasegawa $Y$, Nikai T, Yamashita R, Yoshikawa Y, Sugihara H, Ogawa K, Mizuno M: Isolation and characterization of elastolytic proteinase from Aspergillus fumigatus. Jpn J Med Mycol 36: 235-243, 1995.

3) Larcher G, Bouchara JP, Annaix V, Symoens F, Chabasse D, Tronchin G: Purification and characterization of a fibrinogenolytic serine proteinase from Aspergillus fumigatus culture filtrate. FEBS 308: 65-69, 1992.

4) Monod M, Paris S, Sangland D, Jaton-ogay K, Bille J, Latge JP: Isolation and characterization of secreted metalloprotease of Aspergillus fumigatus. Infect Immun 61: 4099-4104, 1993.

5) Monod M, Togni G, Rahalison L, Frenk E: Isolation and characterization of an extracellular alkaline protease of Aspergillus fumigatus. J Med Microbiol 35: 23-28, 1991.

6) Rhodes JC, Amlung TW, Miller MS: Isolation and characterization of an elastinolytic proteinase from Aspergillus flavus. Infect Immun 58: 25292534, 1990.

7) Hasegawa Y, Nikai T, Okumura Y, Ogawa K, Sugihara H: Characterization of elastolytic proteinase from Aspergillus flavus: comparison of the elastolytic proteinase from Aspergillus fumigatus. Jpn J Med Mycol 38: 53-59, 1997.

8) Takahashi $K$, Inoue $H$, Sakai $K$, Kohama $T$, Kitahara S, Takishima K, Tanji M, Athauda SB 
P, Takahashi T, Akanuma H, Mamiya G, Yamasaki M: The primary structure of Aspergillus niger acid proteinase A. J Biol Chem 266: 19480 -19483, 1991.

9) Inoue $\mathrm{H}$, Kimura $\mathrm{T}$, Kitahara $\mathrm{S}$, Makabe $\mathrm{O}$, Takahashi K: The gene and deduced protein sequences of the zymogene of Aspergillus niger acid proteinase A. J Biol Chem 266: 1948419489, 1991.

10) Kothary MH, Chase $\mathrm{T}$ Jr, Macmillan JD: Correlation of elastase production by some strains of Aspergillus fumigatus with ability to cause pulmonary invasive aspergillosis in mice. Infect Immun 43: 320-325, 1984.

11) Reichard U, Buttner S, Eiffert H, Staib F, Ruchel R: Purification and characterization of an extracellular serine proteinase from Aspergillus fumigatus and its detection in tissue. J Med Microbiol 33: 243-251, 1990.

12) Blanco JL, Hontecillas R, Bouza E, Blanco I, Pelaez T, Munoz P, Molina JP, Garcia ME: Correlation between the elastase activity index and invasiveness of clinical isolate of Aspergillus fumigatus. J Clin Microbiol 40: 1811-1813, 2002.

13) Frosco M, Fahed C, Chase T Jr, Macmillan JD: Inhibition of Aspergillus fumigatus elastase with monoclonal antibodies produced by using denatured elastase as an immunogen. Infect Immun 60: 735-741, 1992.

14) Hasegawa $Y$, Nikai $T$, Yoshikawa $Y$, Sugihara $H$, Ogawa K, Takagi K: Elastase activity from Aspergillus species and inhibition by urinastatin. Jpn J Med Mycol 35: 293-298, 1994.

15) Maesaki S, Kohno S, Tanaka K, Miyazaki H, Mitsutake K, Miyazaki T, Tomono K, Kaku M, Koga H, Hara K: A case of pulmonary aspergilloma successfully treated with combination therapy of intracavitary injection of amphotericin B and intravenous administration of urinastatin. Nihon Kyobu Shikkan Gakkai Zasshi 31: 1327-1331, 1993. (in Japanese)

16) Ogawa K: Treatment of chronic pulmonary aspergillosis. Kekkaku 72: 59-64, 1997. (in Japanese)

17) Ogawa K., Taki F, Takagi K, Furui H, Tsuda M, Honda K, Sasaki T, Sasamoto M, Miwa T: Study of elastase production by Aspergillus species and inhibition of their elastase activity by drugs. Kokyuu 11: $880-886$, 1992. (in Japanese)

18) Sugimura S, Yoshida K, Oba H, Hashiguchi K, Nakajima M, Moriya O, Okimoto N, Niki Y, Soejima R: Two cases of invasive pulmonary aspergillosis in non-immunocompromised host. Nihon Kyobu Shikkan Gakkai Zasshi 32: 10321037, 1994. (in Japanese)

19) Okumura $Y$, Ogawa K, Nikai T: Elastase and elastase inibitor from Aspergillus fumigatus, Aspergillus flavus and Aspergillus niger. J Med Mycol 53: 351-354, 2004.

20) Morris DL: Quantitative determination of carbohydrates with dreywood's anthrone reagent. Science 107: 254-255, 1948.

21) Ouyang C, Teng CM: Fibrinogenolytic enzymes of Trimeresurus mucrosquamatus venom. Biochim Biophys Acta 42: 298-308, 1974.

22) Komori $Y$, Nonogaki $T$, Nikai $T$ : Hemorrhagic activity and muscle damaging effect of Pseudomonas aeruginosa metalloproteinase (elastase). Toxicon 39: 1327-1332, 2001.

23) Nikai T, Sugihara H, Tanaka T: Enzymochemical studies on snake venoms-II. Purification of lethal protein Ac1-Proteinase in the venom of Agkistrodon acutus. Yakugaku Zasshi 97: 507514, 1977. (in Japanese)

24) Kolattukudy PE, Lee JD, Rogers LM, Zimmerman $\mathrm{P}$, Ceselski S, Fox B, Stein B, Copelan EA: Evidence for possible involvement of an elastolytic serine protease in aspergillosis. Infect Immun 61: 2357-2368, 1993.

25) Kawabata K, Suzuki M, Sugitani M, Imaki K, Toda M, Miyamoto T: ONO-5046, A novel inhibitor of human neutrophil elastase. Biochem Biophys Res Commun 177: 814-820, 1991. 